\title{
Impact of parental cancer on IQ, stress resilience, and physical fitness in young men
}

This article was published in the following Dove Press journal:

Clinical Epidemiology

\author{
Ruoqing Chen' \\ Katja Fall ${ }^{1,2}$ \\ Kamila Czene' \\ Beatrice Kennedy ${ }^{2}$ \\ Unnur Valdimarsdóttir ${ }^{1,3,4}$ \\ Fang Fang' \\ 'Department of Medical Epidemiology \\ and Biostatistics, Karolinska Institutet, \\ Stockholm, Sweden; ${ }^{2}$ Clinical \\ Epidemiology and Biostatistics, \\ School of Medical Sciences, Örebro \\ University, Örebro, Sweden; ${ }^{3}$ Centre \\ of Public Health Sciences, Faculty \\ of Medicine, University of Iceland, \\ Reykjavík, Iceland; ${ }^{4}$ Department of \\ Epidemiology, Harvard TH Chan \\ School of Public Health, Boston, MA, \\ USA
}

Background: A parental cancer diagnosis is a stressful life event, potentially leading to increased risks of mental and physical problems among children. This study aimed to investigate the associations of parental cancer with IQ, stress resilience, and physical fitness of the affected men during early adulthood.

Materials and methods: In this Swedish population-based study, we included 465,249 men born during 1973-1983 who underwent the military conscription examination around the age of 18 years. We identified cancer diagnoses among the parents of these men from the Cancer Register. IQ, stress resilience, and physical fitness of the men were assessed at the time of conscription and categorized into three levels: low, moderate, and high (reference category). We used multinomial logistic regression to assess the studied associations.

Results: Overall, parental cancer was associated with higher risks of low stress resilience (relative risk ratio [RRR]: 1.09 [95\% confidence interval (CI) 1.04-1.15]) and low physical fitness (RRR: 1.12 [95\% CI 1.05-1.19]). Stronger associations were observed for parental cancer with a poor expected prognosis (low stress resilience: RRR: 1.59 [95\% CI 1.31-1.94]; low physical fitness: RRR: 1.45 [95\% CI 1.14-1.85]) and for parental death after cancer diagnosis (low stress resilience: RRR: 1.29 [95\% CI 1.16-1.43]; low physical fitness: RRR: 1.40 [95\% CI 1.23-1.59]). Although there was no overall association between parental cancer and IQ, parental death after cancer diagnosis was associated with a higher risk of low IQ (RRR: 1.11 [95\% CI 1.01-1.24]). Conclusion: Parental cancer, particularly severe and fatal type, is associated with higher risks of low stress resilience and low physical fitness among men during early adulthood. Men who experienced parental death after cancer diagnosis also have a higher risk of low IQ.

Keywords: child of impaired parents, cancer, intelligence, resilience, physical fitness

\section{Introduction}

Being diagnosed with cancer is stressful for the patients and their families. ${ }^{1}$ Minor children are the most vulnerable members of a family, because they are undergoing significant physical and neurobehavioral development, and therefore particularly susceptible to stress and its negative consequences. ${ }^{2}$ Children living with a parent with cancer have been reported to have impaired well-being, including psychological and psychiatric problems such as low self-esteem and internalizing and externalizing symptoms, and physical problems such as pain, dizziness, and injury. ${ }^{3-9}$ Although knowledge about the well-being of children with parental cancer is being accumulated, many domains of health in these children have yet to be studied.

A specific impact of parental cancer on minor children is biologically plausible, not only because of the great dependence of the children on their parents but also because
Correspondence: Ruoqing Chen Department of Medical Epidemiology and Biostatistics, Karolinska Institutet, PO Box 28I, SE-I7I 77, Stockholm, Sweden Tel +46852486131

Fax +468314975

Email ruoqing.chen@ki.se 
of the particular sensitivity of the developing brain to stress. ${ }^{10}$ Intelligence is highly correlated with the neuroanatomy of the brain, and it exerts lifelong powerful influences on various aspects of life. ${ }^{11,12}$ Parenting style and early life stress might both modulate childhood intelligence. ${ }^{13,14}$ Diminished school performance has been reported among children with parental cancer, ${ }^{15}$ but whether this could possibly be driven by decreased intelligence has not been addressed. Stress symptoms have been reported among children with parental cancer, ${ }^{16}$ but it remains unknown whether parental cancer influences children's capacity to cope with future challenges in terms of stress resilience. ${ }^{17}$ In addition to intellectual and psychological development, childhood is also a critical time window for physical growth, with developing cardiorespiratory endurance, muscular endurance, muscular strength, body composition, and flexibility ${ }^{18}$ As a severe illness in a parent might induce alterations in the daily routines of the family, including physical activities and dietary habits, it might also consequently influence the physical growth and fitness of the affected children. ${ }^{19,20}$ Yet, to the best of our knowledge, whether parental cancer has a negative impact on children's physical fitness has not been studied.

Using a nationwide register-based study design, we aimed to investigate the associations of parental cancer with IQ, stress resilience, and physical fitness among men who underwent a mandatory military conscription examination during early adulthood. We were particularly interested in assessing whether the associations varied by the sex of the parent with cancer, the man's age at the diagnosis of parental cancer, or the prognosis and fatality of parental cancer. We also aimed to assess whether the associations were independent of birth characteristics of the men and sociodemographic characteristics of the men and their parents.

\section{Materials and methods}

\section{Study participants}

Using the unique Swedish personal identity numbers, we linked data across the Swedish Multi-Generation Register, Conscription Register, Cause of Death Register, Migration Register, Cancer Register, Medical Birth Register, Register of Education, Population and Housing Census, and Patient Register.

The Multi-Generation Register contains information on all Swedish residents who were born in 1932 or later and alive in 1961, together with their parents. ${ }^{21}$ According to Swedish law, the military conscription was mandatory for men at the age of 18 years. From 2002/2003, the number of conscripts declined dramatically due to reduced need of military, and from 2010 onward, the conscription has been officially suspended. ${ }^{22}$ Therefore, we included men born in Sweden during 1973-1983 ( $\mathrm{N}=557,579)$, and linked these men to the Conscription Register. A total of $88.3 \%$ of the men had undergone the conscription examination during 1990-2010 $(\mathrm{N}=492,152$, age [mean $=18.2$ years, range $=16.7-32.5$ years]). Among the 65,427 men who were excluded, 21,997 had died or emigrated from Sweden before the age of 18 years, and 43,430 were either exempt from conscription due to severe mental and physical conditions or incarceration, or unidentifiable due to other reasons. ${ }^{23}$ We identified the parents of the 492,152 men, and only those with complete information on parents' identity were included $(\mathrm{N}=487,468)$. Men with a parent who was diagnosed with cancer before or on the date of their birth and men with missing or invalid data on all assessments for IQ, stress resilience, and physical fitness were excluded, leaving 465,249 men in the final analysis (Figure 1).

The study was approved by the Central Ethical Review Board in Stockholm, Sweden, and individual informed consent from the study participants was waived according to this decision. All information was anonymized and de-identified prior to analysis.

\section{Exposure assessment}

We linked both parents of the men to the Cancer Register, and identified the date of first cancer diagnosis, if any. Cancer types were coded according to the 7th Swedish revision of the International Classification of Diseases (ICD). As we aimed to assess the impact of exposure to newly diagnosed parental cancer during childhood, men with a parent who was diagnosed with cancer before or on the date of their birth were excluded ( $\mathrm{N}=2,005$; Figure 1). In case that both parents had a cancer diagnosis $(\mathrm{N}=313)$, the first diagnosed cancer among the parents was used. Men with a parental cancer diagnosis before their conscription comprised the exposed group, whereas men without parental cancer diagnosis before conscription comprised the unexposed group. As cancer-related characteristics have been shown to modify children's adjustment to parental cancer, ${ }^{24}$ we further categorized the exposed group according to 1) sex of the parent with cancer, 2) man's age at the time of parental cancer diagnosis, 3) expected prognosis of the cancer (Table S1), and 4) death of the parent with cancer after cancer diagnosis.

\section{Outcome assessment}

The Conscription Register includes information from the conscription examination, which included extensive intellectual, 


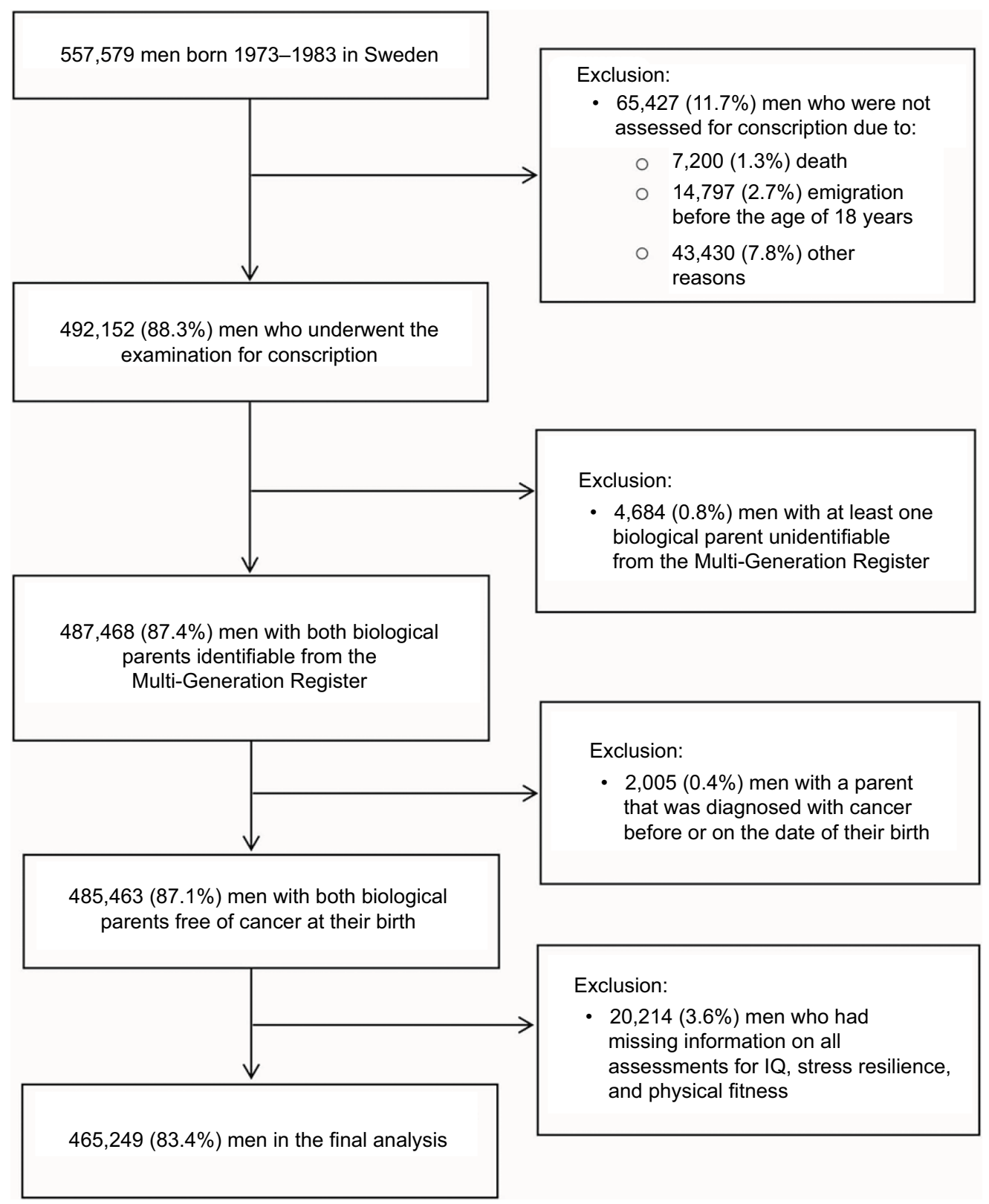

Figure I Flow chart of inclusion and exclusion of study subjects.

psychological, physical, and medical assessments. ${ }^{25}$ IQ, stress resilience, and physical fitness were assessed during the examination.

\section{IQ}

IQ was assessed in the conscripts using three different test versions during the study period (Supplementary materials). ${ }^{26,27}$ The overall contents of the three tests were largely similar, and the subtests can be described in general terms. ${ }^{28} \mathrm{~A}$ test for inductive ability measured the capacity to understand written instructions and to apply them to problem solving. A verbal test measured the ability to determine the synonym of a given word. A spatial test measured the ability to determine the correct three-dimensional object from a series of twodimensional drawings. A technical test measured knowledge of mathematics and physics. A global IQ score was generated by combining scores from the subtests. The global IQ score was standardized against the entire population and followed a Gaussian distribution with values between one and nine (i.e., Stanine scale). A higher value indicated greater IQ. The global scale has been shown to have satisfactory construct validity and reliability to measure the general intellectual capacity. ${ }^{26}$ We categorized the scores into low (1-3), moderate (4-6), and high (7-9), as previously suggested. ${ }^{29}$ 


\section{Stress resilience}

All men underwent a 25-minute semi-structured interview performed by a psychologist to assess their ability to cope with psychological stress during military service. ${ }^{30}$ Mental energy, emotional control, social maturity, and active/passive interests were rated by the psychologist and combined to produce a summarized stress resilience score on a Stanine scale where a higher value indicated better functioning. We grouped the scores into low (1-3), moderate (4-6), and high (7-9), as previously suggested. ${ }^{31}$ To ensure uniform assessment across different conscription centers, a written instruction was used and supervision was conducted by a central authority. ${ }^{31}$ The stress resilience assessment demonstrated high inter-rater reliability. ${ }^{32,33}$

\section{Physical fitness}

Physical fitness was assessed using an electrically braked bicycle ergometer, which has been widely used to study physical working capacity during a short, graded exercise test. ${ }^{34}$ After a normal resting electrocardiography, the men continued with the maximal work test with gradually increasing resistance until one had to discontinue due to exhaustion. ${ }^{35}$ The maximum load that the men could sustain for 6 minutes was estimated as a measure of physical fitness. ${ }^{35}$ The resulting values in Watts were transformed into scores from zero to nine. A higher value indicated greater physical fitness. Because the mean of physical fitness was six with a standard deviation of 1.5 , we categorized the scores into low (0-4), moderate (5-7), and high (8-9). The measurement of physical fitness was shown to have both good validity and reliability. ${ }^{35,36}$

\section{Other measures}

Various characteristics of the men and their parents might be related to both the risk of parental cancer and the risks of the studied outcomes, and as a result confound or modify the studied associations. ${ }^{19,24,37-42}$ We obtained information on gestational age at birth and birth weight of the men, and maternal age at the man's birth from the Medical Birth Register. We obtained information on paternal age at the time of man's birth from the Multi-Generation Register. The educational levels for both parents were retrieved from the Register of Education from 1985. The parental socioeconomic statuses were extracted from the Swedish Population and Housing Census in 1980 and categorized according to the socioeconomic classification system of Statistics Sweden. ${ }^{43}$ We extracted information from the Patient Register on any diagnosis of psychiatric disorder among the parents before the date of conscription. The diagnosis was recorded using the Swedish revisions of ICD codes (Table S2).

\section{Statistical analyses}

\section{Primary analyses}

We used the multinomial logistic regression to assess the associations of parental cancer with IQ, stress resilience, and physical fitness. The high levels of the three outcomes were used as the reference category. The relative risk ratios (RRRs) with 95\% confidence interval (CI) for low or moderate IQ/stress resilience/physical fitness relative to high IQ/stress resilience/physical fitness between the exposed and unexposed groups were estimated with adjustment for birth year, conscription year, birth characteristics of the men, educational level and socioeconomic status of the parents, and age of the parents at the man's birth. To account for the correlation among men with the same parents, we applied "clustered" (sandwich) standard errors in all models.

In addition, we assessed the possible modifying effects of cancer-related characteristics on the studied associations, by means of one model per characteristic. Dose-response relationships between the expected prognosis of parental cancer and the three outcomes were assessed via Wald tests by fitting models with the expected prognosis as a continuous variable.

To examine the impact of using different IQ tests during the conscription period, we performed formal tests for the interaction between parental cancer and three calendar periods when different tests were used. We also tested the interaction between parental cancer and parental psychiatric history to assess whether the studied associations differed between men with and without a parental history of psychiatric disorder.

\section{Secondary analyses}

In this study, IQ, stress resilience, and physical fitness were correlated with each other (Pearson correlation: IQ and stress resilience, $r=0.37$; IQ and physical fitness, $r=0.20$; stress resilience and physical fitness, $r=0.45$ ). Previous studies have also suggested that intelligence, psychological functioning, or physical health may be consequent of each other among children with parental illness. ${ }^{446}$ We therefore performed secondary analyses to assess whether the impact of parental cancer on one outcome was independent of the other two outcomes. For example, when we estimated the RRRs for 
IQ, we additionally adjusted for both stress resilience and physical fitness in the model.

Given the fact that a small subgroup of the exposed men had two parents with cancer, we performed another set of secondary analyses to assess whether the studied associations differed between one parental cancer and two parental cancers.

The data preparation was performed with SAS version 9.4, SAS institute Inc. The statistical analyses were performed with Stata version 14.0, StataCorp LP.

\section{Results}

A total of 20,383 men (4.4\%) had a parent diagnosed with cancer after their birth and before conscription. The characteristics of the men and their parents are presented in Table 1.

\section{IQ}

Although the exposed men appeared to have a higher IQ than the unexposed group (Table 2), no overall association was observed between parental cancer and IQ after multivariable adjustment (Table 3). A dose-response relationship between the expected prognosis of parental cancer and low IQ was, however, suggested. A positive association was also noted between death of the parent with cancer and low IQ (RRR: 1.11 [95\% CI 1.01-1.24]). Use of different IQ tests did not modify the results (Table S3).

\section{Stress resilience}

Among the men with parental cancer, $21.4 \%$ had low stress resilience; the proportion was $19.8 \%$ among the unexposed men (Table 2). Parental cancer was associated with a higher risk of low stress resilience (RRR: 1.09 [95\% CI 1.04-1.15]) (Table 3 ). This risk increment was particularly pronounced among men with parental cancer who had a poor expected prognosis, among men who lost the parent with cancer due to death, and among men who were 6-12 years of age when a parent was diagnosed with cancer. A clear dose-response relationship between the expected prognosis of cancer and low stress resilience was also observed.

\section{Physical fitness}

The exposed men were more likely to have low physical fitness than the unexposed men (Table 2). In the multivariable analysis, parental cancer was associated with higher risks of moderate (RRR: 1.10 [95\% CI 1.05-1.16]) and low (RRR: 1.12 [95\% CI 1.05-1.19]) physical fitness (Table 3). Dose-response relationships of the expected prognosis of cancer with both moderate and low physical fitness were
Table I Characteristics of the participating men and their parents $(\mathrm{N}=465,249)$

\begin{tabular}{|c|c|c|}
\hline Characteristics & $\begin{array}{l}\text { Men with } \\
\text { parental cancer } \\
(\mathrm{N}=\mathbf{2 0 , 3 8 3 )}\end{array}$ & $\begin{array}{l}\text { Men without } \\
\text { parental cancer } \\
(\mathrm{N}=444,866)\end{array}$ \\
\hline \multicolumn{3}{|l|}{ Men } \\
\hline \multicolumn{3}{|l|}{ Gestational age (weeks) } \\
\hline$<35$ & $363(1.8)$ & $7,043(1.6)$ \\
\hline $35-36$ & 727 (3.6) & $14,784(3.3)$ \\
\hline $37-38$ & $3,478(17.1)$ & $68,558(15.4)$ \\
\hline $39-40$ & $9,671(47.5)$ & $212,077(47.7)$ \\
\hline $4 I-42$ & $5,438(26.7)$ & $125,493(28.2)$ \\
\hline$\geq 43$ & $419(2.1)$ & $10,794(2.4)$ \\
\hline Missing & $287(1.4)$ & $6,117(1.4)$ \\
\hline \multicolumn{3}{|l|}{ Birth weight (g) } \\
\hline$<2,500$ & $668(3.3)$ & $14,062(3.2)$ \\
\hline $2,500-2,999$ & $1,930(9.5)$ & $42,544(9.6)$ \\
\hline $3,000-3,499$ & $5,824(28.6)$ & $133,755(30.1)$ \\
\hline $3,500-3,999$ & $7,306(35.8)$ & 159,659 (35.9) \\
\hline $4,000-4,499$ & $3,50 I(I 7.2)$ & $73,006(16.4)$ \\
\hline$\geq 4,500$ & $908(4.5)$ & $16,801(3.8)$ \\
\hline Missing & $246(1.2)$ & $5,039(1.1)$ \\
\hline \multicolumn{3}{|l|}{ Parents } \\
\hline \multicolumn{3}{|l|}{ Paternal educational level } \\
\hline Primary school or lower & $7,128(35.0)$ & $164,658(37.0)$ \\
\hline Secondary education & $7,663(37.6)$ & $|78,9| 4(40.2)$ \\
\hline $\begin{array}{l}\text { Tertiary or postgraduate } \\
\text { education }\end{array}$ & $4,764(23.4)$ & $95,886(21.6)$ \\
\hline Missing & $828(4.1)$ & $5,408(1.2)$ \\
\hline \multicolumn{3}{|l|}{ Maternal educational level } \\
\hline Primary school or lower & $6,542(32.1)$ & $|50,76|(33.9)$ \\
\hline Secondary education & $8,026(39.4)$ & $189,927(42.7)$ \\
\hline $\begin{array}{l}\text { Tertiary or postgraduate } \\
\text { education }\end{array}$ & $5,199(25.5)$ & $102,392(23.0)$ \\
\hline Missing & $616(3.0)$ & $\mathrm{I}, 786(0.4)$ \\
\hline \multicolumn{3}{|l|}{ Paternal socioeconomic status } \\
\hline Blue-collar & $7,864(38.6)$ & $197,754(44.5)$ \\
\hline White-collar & $8,377(41.1)$ & $166,119(37.3)$ \\
\hline $\begin{array}{l}\text { Self-employed including } \\
\text { farmers }\end{array}$ & $2,220(10.9)$ & $43,837(9.9)$ \\
\hline Others & $807(4.0)$ & $16,430(3.7)$ \\
\hline Missing & $\mathrm{I}, \mathrm{I} I 5(5.5)$ & $20,726(4.7)$ \\
\hline \multicolumn{3}{|l|}{ Maternal socioeconomic status } \\
\hline Blue-collar & $4,712(23.1)$ & I 19,470 (26.9) \\
\hline White-collar & $7,269(35.7)$ & $145,529(32.7)$ \\
\hline $\begin{array}{l}\text { Self-employed including } \\
\text { farmers }\end{array}$ & $703(3.5)$ & $12,345(2.8)$ \\
\hline Others & $5,886(28.9)$ & $131,6 \mid 2(29.6)$ \\
\hline Missing & $1,813(8.9)$ & $35,910(8.1)$ \\
\hline \multicolumn{3}{|c|}{ Paternal age at the man's birth (years) } \\
\hline$<20$ & $72(0.4)$ & $4,734(1.1)$ \\
\hline $20-24$ & I,708 (8.4) & $73,281(16.5)$ \\
\hline $25-29$ & $5,664(27.8)$ & $168,067(37.8)$ \\
\hline $30-34$ & $6,473(31.8)$ & $|27,83|(28.7)$ \\
\hline$\geq 35$ & $6,466(31.7)$ & $70,953(16.0)$ \\
\hline \multicolumn{3}{|c|}{ Maternal age at the man's birth (years) } \\
\hline$<20$ & $493(2.4)$ & $24,319(5.5)$ \\
\hline $20-24$ & $3,469(17.0)$ & $130,606(29.4)$ \\
\hline $25-29$ & $6,950(34.1)$ & $|68,93|(38.0)$ \\
\hline $30-34$ & $6,101(29.9)$ & $90,835(20.4)$ \\
\hline$\geq 35$ & $3,370(16.5)$ & $30,175(6.8)$ \\
\hline
\end{tabular}

Note: Data are presented as $n(\%)$ of men. 
observed. The death of the parent with cancer conferred even higher risks of moderate and low physical fitness.

The overall associations of parental cancer with IQ, stress resilience, and physical fitness were not modified by the parental history of psychiatric disorder (Table S4).

Table 2 IQ, stress resilience, and physical fitness of the participating men $(\mathrm{N}=465,249)$

\begin{tabular}{lll}
\hline $\begin{array}{l}\text { Conscription } \\
\text { characteristics }\end{array}$ & $\begin{array}{l}\text { Men with } \\
\text { parental cancer } \\
(\mathbf{N}=\mathbf{2 0 , 3 8 3})\end{array}$ & $\begin{array}{l}\text { Men without } \\
\text { parental cancer } \\
\mathbf{( N = 4 4 4 , 8 6 6 )}\end{array}$ \\
\hline IQ & $5,055(24.8)$ & $104,974(23.6)$ \\
High (7-9) & $10,927(53.6)$ & $241,109(54.2)$ \\
Moderate (4-6) & $4,107(20.1)$ & $93,515(21.0)$ \\
Low (I-3) & $294(1.4)$ & $5,268(1.2)$ \\
Missing & & \\
Stress resilience & $3,910(19.2)$ & $86,098(19.4)$ \\
High (7-9) & $10,016(49.1)$ & $224,593(50.5)$ \\
Moderate (4-6) & $4,357(21.4)$ & $87,897(19.8)$ \\
Low (I-3) & $2,100(10.3)$ & $46,278(10.4)$ \\
Missing & & \\
Physical fitness & $2,758(13.5)$ & $66,156(14.9)$ \\
High (8-9) & $12,639(62.0)$ & $277,844(62.5)$ \\
Moderate (5-7) & $2,799(13.7)$ & $58,877(13.2)$ \\
Low (0-4) & $2,187(10.7)$ & $41,989(9.4)$ \\
Missing &
\end{tabular}

Note: Data are presented as $\mathrm{n}(\%)$ of men.

\section{Secondary analyses}

After mutual adjustment of all three outcomes, the associations between parental cancer and physical fitness remained largely unchanged (Table 4). The associations for IQ and stress resilience were largely attenuated to null, except for the associations of stress resilience with parental cancer with a poor expected prognosis, parental cancer that led to the death of the parent with cancer, and parental cancer that was diagnosed when the men were 6-12 years of age (Table 4).

Among the men with parental cancer, $1.5 \%(\mathrm{~N}=313)$ experienced two parental cancers before conscription. The overall associations of one parental cancer with the three outcomes remained the same as in the primary analyses. No associations were, however, observed for two parental cancers (Table S5).

\section{Discussion}

To the best of our knowledge, we are the first to investigate whether parental cancer is associated with IQ, stress resilience, and physical fitness of the affected children during early adulthood. In this Swedish register-based study, parental cancer was associated with low stress resilience and low physical fitness among the affected men, with stronger associations observed for parental cancer with a poor expected prognosis, and a loss

Table 3 Relative risk ratios and 95\% confidence intervals for IQ, stress resilience, and physical fitness comparing men with and without parental cancer $(\mathrm{N}=465,249)$

\begin{tabular}{|c|c|c|c|c|c|c|}
\hline \multirow[t]{2}{*}{ Characteristics } & \multicolumn{2}{|l|}{ IQ } & \multicolumn{2}{|l|}{ Stress resilience } & \multicolumn{2}{|l|}{ Physical fitness } \\
\hline & Moderate (4-6) & Low $(I-3)$ & Moderate (4-6) & Low $(1-3)$ & Moderate (5-7) & Low (0-4) \\
\hline No parental cancer & Ref & Ref & Ref & Ref & Ref & Ref \\
\hline Parental cancer & $1.00(0.96-1.04)$ & $1.02(0.97-1.08)$ & $0.99(0.95-1.03)$ & $1.09(1.04-1.15)$ & $1.10(1.05-1.16)$ & $1.12(1.05-1.19)$ \\
\hline \multicolumn{7}{|c|}{ Sex of the parent with cancer } \\
\hline Mother & $1.00(0.95-1.05)$ & $1.02(0.96-1.09)$ & $0.99(0.94-1.05)$ & $1.10(1.03-1.17)$ & $1.12(1.05-1.19)$ & $1.14(1.05-1.23)$ \\
\hline Father & $1.00(0.94-1.07)$ & $1.02(0.94-1.10)$ & $0.98(0.92-1.05)$ & $1.08(1.00-1.17)$ & $1.08(1.00-1.17)$ & $1.10(0.99-1.21)$ \\
\hline \multicolumn{7}{|c|}{$\begin{array}{l}\text { Man's age at parental cancer } \\
\text { diagnosis (years) }\end{array}$} \\
\hline$<6$ & $1.01(0.91-1.12)$ & $0.98(0.85-1.12)$ & $0.93(0.84-1.04)$ & $1.05(0.92-1.19)$ & $1.17(1.03-1.32)$ & $1.15(0.98-1.36)$ \\
\hline $6-12$ & $0.99(0.93-1.05)$ & $0.98(0.91-1.07)$ & $1.00(0.93-1.07)$ & $1.13(1.04-1.23)$ & $1.06(0.98-1.14)$ & $1.07(0.97-1.18)$ \\
\hline$\geq 13$ & $1.01(0.96-1.07)$ & $1.06(0.99-1.14)$ & $0.99(0.94-1.05)$ & $1.08(1.00-1.16)$ & $1.12(1.05-1.20)$ & $1.15(1.06-1.26)$ \\
\hline \multicolumn{7}{|c|}{ Expected prognosis of the } \\
\hline \multicolumn{7}{|c|}{ cancer of the parent $\mathrm{t}^{\mathrm{a}}$} \\
\hline Poor & $1.00(0.85-1.16)$ & $1.20(1.00-1.43)$ & $1.21(1.01-1.45)$ & $1.59(1.31-1.94)$ & $1.37(1.12-1.68)$ & $1.45(1.14-1.85)$ \\
\hline Moderate & $1.05(0.99-1.12)$ & $1.09(1.01-1.18)$ & $0.97(0.91-1.04)$ & $1.09(1.01-1.18)$ & $1.12(1.04-1.21)$ & $1.19(1.09-1.31)$ \\
\hline Good & $0.96(0.91-1.02)$ & $0.93(0.87-1.01)$ & $0.98(0.92-1.04)$ & $1.03(0.96-1.11)$ & $1.06(0.99-1.13)$ & $1.02(0.94-1.12)$ \\
\hline \multirow{2}{*}{\multicolumn{7}{|c|}{$\begin{array}{l}\text { Death of the parent with } \\
\text { cancer after cancer diagnosis }\end{array}$}} \\
\hline & & & & & & \\
\hline Yes & $1.05(0.96-1.14)$ & I.II (I.0I-I.24) & $1.00(0.92-1.10)$ & $1.29(1.16-1.43)$ & $1.24(1.11-1.38)$ & $1.40(1.23-1.59)$ \\
\hline No & $0.99(0.95-1.03)$ & $0.99(0.94-1.05)$ & $0.98(0.94-1.03)$ & $1.03(0.98-1.10)$ & $1.07(1.02-1.13)$ & $1.05(0.98-1.13)$ \\
\hline
\end{tabular}


Table 4 Relative risk ratios and $95 \%$ confidence intervals for IQ, stress resilience, and physical fitness comparing men with and without parental cancer, after mutually adjusting for one another $(\mathrm{N}=465,249)$

\begin{tabular}{|c|c|c|c|c|c|c|}
\hline \multirow[t]{2}{*}{ Characteristics } & \multicolumn{2}{|l|}{$\mathbf{I} \mathbf{Q}^{\mathbf{a}}$} & \multicolumn{2}{|l|}{ Stress resilience $^{\mathrm{b}}$} & \multicolumn{2}{|l|}{ Physical fitness $^{c}$} \\
\hline & Moderate (4-6) & Low $(1-3)$ & Moderate (4-6) & Low (1-3) & Moderate (5-7) & Low (0-4) \\
\hline No parental cancer & Ref & Ref & Ref & Ref & Ref & Ref \\
\hline Parental cancer & $1.00(0.96-1.04)$ & $1.00(0.94-1.06)$ & $0.97(0.93-1.01)$ & $1.02(0.96-1.08)$ & $1.11(1.06-1.17)$ & $1.11(1.03-1.19)$ \\
\hline \multicolumn{7}{|c|}{ Sex of the parent with cancer } \\
\hline Mother & $1.01(0.95-1.06)$ & $1.00(0.92-1.08)$ & $0.97(0.91-1.02)$ & $1.00(0.93-1.08)$ & $1.12(1.05-1.19)$ & $1.14(1.04-1.24)$ \\
\hline Father & $0.99(0.93-1.06)$ & $1.00(0.91-1.09)$ & $0.97(0.91-1.04)$ & $1.04(0.94-1.14)$ & $1.09(1.01-1.18)$ & $1.06(0.95-1.18)$ \\
\hline \multicolumn{7}{|c|}{$\begin{array}{l}\text { Man's age at parental cancer } \\
\text { diagnosis (years) }\end{array}$} \\
\hline$<6$ & $1.02(0.91-1.13)$ & $0.99(0.84-1.16)$ & $0.90(0.80-1.01)$ & $0.97(0.83-1.13)$ & $1.21(1.06-1.38)$ & $1.18(0.99-1.42)$ \\
\hline $6-12$ & $0.99(0.92-1.06)$ & $0.95(0.86-1.04)$ & $1.00(0.93-1.07)$ & $1.11(1.01-1.22)$ & $1.05(0.97-1.14)$ & $1.03(0.92-1.15)$ \\
\hline$\geq 13$ & $1.01(0.95-1.07)$ & $1.04(0.95-1.13)$ & $0.97(0.91-1.03)$ & $0.97(0.89-1.05)$ & $1.13(1.05-1.21)$ & $1.15(1.04-1.26)$ \\
\hline \multicolumn{7}{|c|}{$\begin{array}{l}\text { Expected prognosis of the } \\
\text { cancer of the parent }\end{array}$} \\
\hline Poor & $0.95(0.80-1.12)$ & $1.04(0.85-1.27)$ & I. 18 (0.99-I.42) & $1.41(1.13-1.75)$ & $1.26(1.02-1.54)$ & $1.27(0.98-1.65)$ \\
\hline Moderate & $1.05(0.99-1.12)$ & $1.06(0.97-1.16)$ & $0.94(0.88-1.01)$ & $0.99(0.91-1.08)$ & $1.14(1.05-1.22)$ & $1.19(1.07-1.31)$ \\
\hline Good & $0.97(0.91-1.03)$ & $0.94(0.86-1.02)$ & $0.97(0.91-1.03)$ & $0.99(0.91-1.08)$ & $1.07(1.00-1.15)$ & $1.02(0.92-1.12)$ \\
\hline \multicolumn{7}{|c|}{$\begin{array}{l}\text { Death of the parent with } \\
\text { cancer after cancer diagnosis }\end{array}$} \\
\hline Yes & $1.02(0.93-1.11)$ & $1.04(0.92-1.17)$ & $0.96(0.87-1.05)$ & $1.13(1.00-1.27)$ & $1.23(1.10-1.37)$ & $1.32(1.14-\mid .52)$ \\
\hline No & $1.00(0.95-1.05)$ & $0.99(0.92-1.05)$ & $0.97(0.92-1.02)$ & $0.98(0.92-1.05)$ & $1.08(1.02-1.14)$ & $1.05(0.97-1.14)$ \\
\hline
\end{tabular}

Notes: All models adjusted for birth year, conscription year, gestational age and birth weight of the man, paternal educational level, socioeconomic status and age at the man's birth, and maternal educational level, socioeconomic status, and age at the man's birth. aModel additionally adjusted for stress resilience and physical fitness. ${ }^{b}$ Model additionally adjusted for IQ and physical fitness. 'Model additionally adjusted for IQ and stress resilience. Individual cancer types corresponding to each level of expected prognosis are listed in the Table SI.

of parent due to death after cancer diagnosis. Although there was no overall association between parental cancer and IQ, parental cancer that resulted in the death of the parent was associated with a higher risk of low IQ.

Early stressful life events may yield damaging effects on neural structures, restricting the development of stress resilience. ${ }^{17}$ The emotional and secure attachment with both the ill and healthy parents - an important factor contributing to stress resilience - might also be impaired when both parents are intensively coping with the cancer disease. ${ }^{17} \mathrm{We}$ found a particularly high risk of low stress resilience among men when the parent had a poor expected prognosis or died after the cancer diagnosis. A poor expected prognosis is likely linked to a perception of greater seriousness of the disease, which is associated with more maladaptive coping strategies. ${ }^{47}$ This possibility also seems to coincide with the null association noted for men whose parent was diagnosed when they were very young - a period when the child is not mentally mature to understand the severity of the disease and its related consequences. Children with a genetic susceptibility to psychiatric disorders might be more influenced by parental illness, ${ }^{48}$ potentially explaining the noted association of parental cancer with reduced stress resilience. We found, however, similar associations among children with and without a parental history of psychiatric disorders, further suggesting that the impaired stress resilience in relation to parental cancer is independent of heritable susceptibility to psychiatric disorders.

Given the positive correlation between parental and child physical activity levels, ${ }^{49}$ low physical fitness among the exposed men could be related to reduced daily activity of the diseased parent and the caregiving spouse. Our finding corroborates other studies showing reduced physical functioning in relation to early adversities such as maltreatment. ${ }^{50}$ Stressful life events have been associated with less healthy behaviors, including less physical exercise, increased television watching, and increased smoking and alcohol use..$^{51}$ The dietary and nutrient consumption, which plays a key role in body growth and function, might also be changed after the parent's disease. ${ }^{19}$

In the present study, although no overall association was noted between parental cancer and impaired IQ, a positive association was shown for cancer that resulted in a loss of the parent through death. This result may provide evidence to support the idea that the brain regions responsible for high order function and characterized by long phases of postnatal development are more susceptible to severe psychological stress induced by deprivation of sufficient parenting and even the actual loss of a parent. ${ }^{14}$ 
In the secondary analyses where the three outcomes were mutually adjusted, we found that the overall association was unchanged for physical fitness and diminished for stress resilience. Impaired physical fitness might therefore have contributed to impaired stress resilience in relation to parental cancer. Previous studies have shown that physically fit individuals tend to be better able to tolerate intense workloads and be less susceptible to psychological stress. ${ }^{52}$ Improvement in physical fitness might reduce sensitivity to stress and optimize neuroendocrine stress responsivity. ${ }^{19,52}$ This finding suggests that improving physical fitness among men with parental cancer might also lead to improved stress resilience.

Our study has several strengths. Our findings provide new and important evidence about the cognitive, psychological, and physical well-being of children with parental cancer. The large population-based study design with high-quality register data, together with the independently and prospectively collected information on exposure and outcomes, precludes most of the systematic errors of observational studies. Some limitations should also be discussed. We lacked data on potential confounders of the studied associations, such as cohabitation status of the parents, parenting styles, family cohesion, and non-ill parent's caregiving quality and coping strategies. ${ }^{24,53-57}$ Although almost $90 \%$ of the men born during 1973-1983 participated in the conscription examination, we lacked outcome data on men who did not attend the conscription examination. These excluded men might on average have lower levels of IQ, stress resilience, and physical fitness than the participating men, because exclusions were often based on major mental or physical disabilities. We further found that the excluded men were slightly more likely to have parental cancer $(1,813$ of the 38,903 men whose parents were identifiable [4.7\%]) than those included in the study $(20,383$ of the 465,249 men [4.4\%]). Taking together, these two facts might suggest that the findings are an underestimation of the real impact of parental cancer. Among the men who underwent the conscription examination, a small proportion $(0.8 \%)$ did so after the age of 20 years, with unknown reasons for postponing military enlistment. The findings remain, however, the same with exclusion of these men (data not shown). Although the detailed test manuals for IQ and stress resilience during the conscription examination are classified as military secrets, we believe that these tests are comparable to contemporary tests of their kind. For example, similar to the Connor-Davidson Resilience Scale and the Resilience Scale for Adults, the stress resilience test used in the conscription examination also captured dimensions including emotional stability, persistence, high independence, ability to take initiative, and social capacity to contribute to group cohesion. ${ }^{58,59}$ Finally, potential sex differences have been reported in children's adjustment to parental cancer; ${ }^{24}$ our results, based on a male study population, may therefore not be generalizable to women.

\section{Conclusion}

Our findings suggest that men with parental cancer, especially when the parent with cancer had a poor expected prognosis or died after cancer diagnosis, have higher risks of low stress resilience and low physical fitness than other men during early adulthood. Men who experienced parental death after cancer diagnosis also have a higher risk of low IQ.

\section{Acknowledgments}

This study was supported by the Swedish Research Council for Health, Working Life and Welfare (grant number: 20120498), and the Swedish Cancer Society (grant number: CAN 2014/417). Dr Fang was supported by the Karolinska Institutet (Senior Researcher Award and the Strategic Research Program in Epidemiology). Dr Chen was supported by the China Scholarship Council (no. 201206100002).

\section{Disclosure}

The authors report no conflicts of interest in this work.

\section{References}

1. Lewis FM. The impact of cancer on the family: a critical analysis of the research literature. Patient Educ Couns. 1986;8(3):269-289.

2. Doom JR, Gunnar MR. Stress physiology and developmental psychopathology: past, present, and future. Dev Psychopathol. 2013;25(4 Pt 2): 1359-1373.

3. Grabiak BR, Bender CM, Puskar KR. The impact of parental cancer on the adolescent: an analysis of the literature. Psychooncology. 2007;16(2):127-137.

4. Inhestern L, Bultmann JC, Beierlein V, et al. Understanding parenting concerns in cancer survivors with minor and young-adult children. J Psychosom Res. 2016;87:1-6.

5. Visser A, Huizinga GA, van der Graaf WT, Hoekstra HJ, HoekstraWeebers JE. The impact of parental cancer on children and the family: a review of the literature. Cancer Treat Rev. 2004;30(8):683-694.

6. Osborn T. The psychosocial impact of parental cancer on children and adolescents: a systematic review. Psychooncology. 2007;16(2):101-126.

7. Möller B, Barkmann C, Krattenmacher T, et al. Children of cancer patients: prevalence and predictors of emotional and behavioral problems. Cancer. 2014;120(15):2361-2370.

8. Niemelä M, Paananen R, Hakko H, Merikukka M, Gissler M, Räsänen $\mathrm{S}$. The prevalence of children affected by parental cancer and their use of specialized psychiatric services: the 1987 Finnish Birth Cohort study. Int J Cancer. 2012;131(9):2117-2125.

9. Chen R, Regódon Wallin A, Sjölander A, et al. Childhood injury after a parental cancer diagnosis. Elife. 2015;4:e08500.

10. Lupien SJ, McEwen BS, Gunnar MR, Heim C. Effects of stress throughout the lifespan on the brain, behaviour and cognition. Nat Rev Neurosci. 2009;10(6):434-445. 
11. Batty GD, Deary IJ. Early life intelligence and adult health. BMJ. 2004;329(7466):585-586.

12. Luders E, Narr KL, Thompson PM, Toga AW. Neuroanatomical correlates of intelligence. Intelligence. 2009;37(2):156-163.

13. Bing E. Effect of childrearing practices on development of differential cognitive abilities. Child Dev. 1963;34:631-648.

14. Pechtel P, Pizzagalli DA. Effects of early life stress on cognitive and affective function: an integrated review of human literature. Psychopharmacology (Berl). 2011;214(1):55-70.

15. Rosenfeld A, Caplan G, Yaroslavsky A, Jacobowitz J, Yuval Y, Lebow H. Adaptation of children of parents suffering from cancer: a preliminary study of a new field for primary prevention research. J Prim Prev. 1983;3(4):244-250.

16. Huizinga GA, Visser A, van der GraafWT, et al. Stress response symptoms in adolescent and young adult children of parents diagnosed with cancer. Eur J Cancer. 2005;41(2):288-295.

17. Rutter M. Implications of resilience concepts for scientific understanding. Ann N Y Acad Sci. 2006;1094:1-12.

18. Ortega FB, Ruiz JR, Castillo MJ, Sjöström M. Physical fitness in childhood and adolescence: a powerful marker of health. Int J Obes (Lond). 2008;32(1):1-11.

19. Zaqout M, Vyncke K, Moreno LA, et al. Determinant factors of physical fitness in European children. Int J Public Health. 2016;61(5): 573-582.

20. Buchbinder M, Longhofer J, McCue K. Family routines and rituals when a parent has cancer. Fam Syst Health. 2009;27(3):213-227.

21. Statistics Sweden. Multi-generation register 2010, a description of contents and quality. Available from: http://www.scb.se/statistik/_publikationer/ BE9999_2011A01_BR_BE96BR1102.pdf. Accessed February 12, 2018.

22. Rekryteringsmyndigheten. Historik - Rekryteringsmyndigheten. Available from: http://www.rekryteringsmyndigheten.se/om-rekryteringsmyndigheten/historik/. Accessed February 12, 2018. Swedish.

23. Åberg MA, Waern M, Nyberg J, et al. Cardiovascular fitness in males at age 18 and risk of serious depression in adulthood: Swedish prospective population-based study. Br J Psychiatry. 2012;201(5):352-359.

24. Krattenmacher T, Kühne F, Ernst J, Bergelt C, Romer G, Möller B. Parental cancer: factors associated with children's psychosocial adjustment--a systematic review. J Psychosom Res. 2012;72(5):344-356.

25. Crump C, Sundquist J, Winkleby MA, Sundquist K. Low stress resilience in late adolescence and risk of hypertension in adulthood. Heart. 2016;102(7):541-547.

26. Carlstedt B. Cognitive Abilities - Aspects of Structure, Process and Measurement. Göteborg: Acta Universitatis Gothoburgensis; 2000.

27. Carlstedt B. Mönstring och uttagning till pliktjänst och dess relation till provresultat och psykologbedömningar: en jämförelse mellan svenskar och invandrare. [Testing and enrollment to compulsory service in relation to psychological assessments: a comparison between Swedes and immigrants]. Karlstad: Klara AB Tryckeri i Karlstad; 2002. Swedish.

28. Wennerstad KM, Silventoinen K, Tynelius P, Bergman L, Kaprio J, Rasmussen F. Associations between IQ and cigarette smoking among Swedish male twins. Soc Sci Med. 2010;70(4):575-581.

29. Fowler T, Zammit S, Owen MJ, Rasmussen F. A population-based study of shared genetic variation between premorbid IQ and psychosis among male twin pairs and sibling pairs from Sweden. Arch Gen Psychiatry. 2012;69(5):460-466.

30. Lindqvist E, Vestman R. The labor market returns to cognitive and noncognitive ability: evidence from the Swedish enlistment. Am Econ J Appl Econ. 2011;3(1):101-128.

31. Bergh C, Udumyan R, Fall K, Nilsagård Y, Appelros P, Montgomery S. Stress resilience in male adolescents and subsequent stroke risk: cohort study. J Neurol Neurosurg Psychiatry. 2014;85(12):1331-1336.

32. Lilieblad B, Ståhlberg B. Reliabilitet hos psykologiska bedömningar vid inskrivningsprövning. FOA rapport C55011-H7. Stockholm: Armed Forces Research Department; 1977. Swedish.
33. Carlstedt B. Validering av inskrivningsprövningen mot vitsord från den militära grundutbildningen. [Validation of enlistment variables against military service credentials]. Karlstad: Klara AB Tryckeri i Karlstad; 1999. Swedish.

34. Kokkinos P. Physical fitness evaluation. Am J Lifestyle Med. 2015;9(4):308-317.

35. Nordesjö L, Schéle R. Validity of an ergometer cycle test and measures of isometric muscle strength when prediction some aspects of military performance. Swedish J Defence Med. 1974;10:11-23.

36. Nordesjö LO. Estimation of the maximal work rate sustainable for 6 minutes using a single-level load or stepwise increasing loads. Ups $J$ Med Sci. 1974;79(1):45-50.

37. Innes KE, Byers TE. First pregnancy characteristics and subsequent breast cancer risk among young women. Int J Cancer. 2004;112(2): 306-311.

38. Clegg LX, Reichman ME, Miller BA, et al. Impact of socioeconomic status on cancer incidence and stage at diagnosis: selected findings from the surveillance, epidemiology, and end results: National Longitudinal Mortality Study. Cancer Causes Control. 2009;20(4): 417-435.

39. Saha S, Barnett AG, Buka SL, McGrath JJ. Maternal age and paternal age are associated with distinct childhood behavioural outcomes in a general population birth cohort. Schizophr Res. 2009;115(2-3): $130-135$.

40. Løhaugen GC, Gramstad A, Evensen KA, et al. Cognitive profile in young adults born preterm at very low birthweight. Dev Med Child Neurol. 2010;52(12):1133-1138.

41. Nilsson PM, Nyberg P, Ostergren PO. Increased susceptibility to stress at a psychological assessment of stress tolerance is associated with impaired fetal growth. Int J Epidemiol. 2001;30(1):75-80.

42. Hackman DA, Farah MJ. Socioeconomic status and the developing brain. Trends Cogn Sci. 2009;13(2):65-73.

43. Statistics Sweden. MIS 1982:4. Socioekonomisk indelning (SEI). Available from: http://www.scb.se/statistik/_publikationer/ OV9999_1982A01_BR_X11\%C3\%96P8204.pdf. Accessed February 12, 2018.

44. Cleave H, Charlton A. Evaluation of a cancer-based coping and caring course used in three different settings. Child Care Health Dev. 1997;23(5):399-413.

45. Brustad RJ. Who will go out and play? Parental and psychological influences on children's attraction to physical activity. Pediatr Exerc Sci. 1993;5:210-223.

46. Sieh DS, Meijer AM, Oort FJ, Visser-Meily JM, Van der Leij DA. Problem behavior in children of chronically ill parents: a meta-analysis. Clin Child Fam Psychol Rev. 2010;13(4):384-397.

47. Compas BE, Worsham NL, Ey S, Howell DC. When mom or dad has cancer: II. Coping, cognitive appraisals, and psychological distress in children of cancer patients. Health Psychol. 1996;15(3):167-175.

48. Thastum M, Watson M, Kienbacher C, et al. Prevalence and predictors of emotional and behavioural functioning of children where a parent has cancer: a multinational study. Cancer. 2009;115(17): 4030-4039.

49. Stearns JA, Rhodes R, Ball GD, et al. A cross-sectional study of the relationship between parents' and children's physical activity. $B M C$ Public Health. 2016;16(1):1129.

50. Alastalo H, von Bonsdorff MB, Räikkönen K, et al. Early life stress and physical and psychosocial functioning in late adulthood. PLoS One. 2013;8(7):e69011.

51. Stults-Kolehmainen MA, Sinha R. The effects of stress on physical activity and exercise. Sports Med. 2014;44(1):81-121.

52. Silverman MN, Deuster PA. Biological mechanisms underlying the role of physical fitness in health and resilience. Interface Focus. 2014;4(5):20140040.

53. Woźniak K, Iźycki D. Cancer: a family at risk. Prz Menopauzalny. 2014;13(4):253-261. 
54. Tein JY, Sandler IN, Zautra AJ. Stressful life events, psychological distress, coping, and parenting of divorced mothers: a longitudinal study. J Fam Psychol. 2000;14(1):27-41.

55. Huizinga GA, Visser A, van der GraafWT, Hoekstra HJ, Hoekstra-Weebers JE. The quality of communication between parents and adolescent children in the case of parental cancer. Ann Oncol. 2005;16(12):1956-1961.

56. Cerniglia L, Cimino S, Ballarotto G, Monniello G. Parental loss during childhood and outcomes on adolescents' psychological profiles: a longitudinal study. Curr Psychol. 2014;33(4):545-556.
57. Saldinger A, Porterfield K, Cain AC. Meeting the needs of parentally bereaved children: a framework for child-centered parenting. Psychiatry. 2004;67(4):331-352.

58. Connor KM, Davidson JR. Development of a new resilience scale: the Connor-Davidson Resilience Scale (CD-RISC). Depress Anxiety. 2003;18(2):76-82.

59. Friborg O, Hjemdal O, Rosenvinge JH, Martinussen M. A new rating scale for adult resilience: what are the central protective resources behind healthy adjustment? Int J Methods Psychiatr Res. 2003;12(2):65-76. 


\section{Supplementary materials}

\section{Supplementary method - IQ tests}

During the study period, three different IQ tests were used. ${ }^{1,2}$ The first test was a written questionnaire used during 1969 1994. It consisted of four subtests investigating instructions (inductive), synonyms (verbal), metal folding (spatial), and technical comprehension (technical knowledge). The second test was introduced after 1994, including 10 subtests measuring inductive, verbal, spatial, and technical comprehension abilities. From 2000, a third semi-adaptive version of the second test was used where the degree of difficulty was adjusted according to the man's performance during the test. The overall contents of the three tests were, however, largely similar, generating a global IQ score through combining scores from the subtests.

Table SI Expected prognosis of cancer classified by the predicted 5-year relative survival of each cancer type, according to summarized statistics from the Swedish National Board of Health and Welfare and the Swedish Cancer Society ${ }^{3,4}$

\begin{tabular}{lll}
\hline $\begin{array}{l}\text { Expected } \\
\text { prognosis }\end{array}$ & $\begin{array}{l}\text { Predicted 5-year } \\
\text { relative survival rate }\end{array}$ & Cancer types \\
\hline $\begin{array}{lll}\text { Poor } \\
\text { Moderate }\end{array}$ & $20 \%$ & $\begin{array}{l}\text { Esophagus, liver, gall bladder, biliary tract, pancreas, lung, and stomach } \\
\text { Oral cavity, pharynx, small intestine, colon, rectum, other digestive organs, nose, nasal cavities, } \\
\text { middle ear and accessory sinuses, larynx, mediastinum and other thoracic organs, cervix uteri, ovary } \\
\end{array}$ \\
& $\begin{array}{l}\text { and other female genital organs, prostate and other male genital organs, kidney, bladder and other } \\
\text { urinary organs, eye, brain, bone, connective tissue, non-Hodgkin's lymphoma, multiple myeloma, } \\
\text { leukemia, and unspecified sites }\end{array}$ \\
& Lip, breast, corpus uteri, testis, skin, thyroid and other endocrine glands, and Hodgkin's lymphoma \\
\hline
\end{tabular}

Table S2 Swedish revisions of International Classification of Disease (ICD) codes for clinical diagnosis of psychiatric disorders in parents

\begin{tabular}{lllll}
\hline Characteristics & ICD-7 & ICD-8 & ICD-9 & ICD-10 \\
\hline Calendar years & $1964-1968$ & $1969-1986$ & $1987-1996$ & $1997-$ \\
Codes & $300-326$ & $290-315$ & $290-319$ & F00-F99 \\
\hline
\end{tabular}

Table S3 Relative risk ratios and $95 \%$ confidence intervals for IQ comparing men with and without parental cancer, according to conscription years $(\mathrm{N}=465,249)$

\begin{tabular}{lll}
\hline Characteristics & IQ & Low (I-3) \\
\cline { 2 - 3 } & Moderate (4-6) & $0.97(0.90-1.06)$ \\
\hline Conscription years & $0.99(0.92-1.05)$ & $1.03(0.97-1.11)$ \\
Before 1995 & $1.00(0.95-1.06)$ & $1.10(0.93-1.31)$ \\
1995-2000 & $1.04(0.92-1.18)$ & 0.34 \\
After 2000 & 0.72 & \\
$P$ for interaction
\end{tabular}

Note: All models adjusted for birth year, conscription year, interaction between parental cancer and conscription year, gestational age and birth weight of the man, paternal educational level, socioeconomic status and age at the man's birth, and maternal educational level, socioeconomic status, and age at the man's birth.

Table S4 Relative risk ratios and 95\% confidence intervals for IQ, stress resilience, and physical fitness comparing men with and without parental cancer, according to the parental history of psychiatric disorders $(\mathrm{N}=465,249)$

\begin{tabular}{|c|c|c|c|c|c|c|}
\hline \multirow[t]{2}{*}{ Characteristics } & \multicolumn{2}{|l|}{ IQ } & \multicolumn{2}{|l|}{ Stress resilience } & \multicolumn{2}{|l|}{ Physical fitness } \\
\hline & Moderate (4-6) & Low $(1-3)$ & Moderate (4-6) & Low $(1-3)$ & Moderate (5-7) & Low (0-4) \\
\hline \multicolumn{7}{|l|}{$\begin{array}{l}\text { Parental history of } \\
\text { psychiatric disorder }\end{array}$} \\
\hline Yes & $0.91(0.80-1.03)$ & $0.95(0.82-1.11)$ & $0.96(0.83-1.1 I)$ & $1.04(0.88-1.22)$ & $1.09(0.92-1.29)$ & I.II (0.9I-I.37) \\
\hline No & $1.01(0.97-1.05)$ & $1.02(0.97-1.08)$ & $0.99(0.94-1.03)$ & $1.09(1.03-1.15)$ & $1.10(1.05-1.16)$ & $1.12(1.05-1.19)$ \\
\hline$P$ for interaction & 0.13 & 0.41 & 0.72 & 0.58 & 0.91 & 0.97 \\
\hline
\end{tabular}

Note: All models adjusted for parental history of psychiatric disorder, interaction between parental cancer and parental history of psychiatric disorder, birth year, conscription year, gestational age and birth weight of the man, paternal educational level, socioeconomic status and age at the man's birth, and maternal educational level, socioeconomic status, and age at the man's birth. 
Table S5 Relative risk ratios and 95\% confidence intervals for IQ, stress resilience, and physical fitness comparing men with one or two parental cancers to men without parental cancer $(\mathrm{N}=465,249)$

\begin{tabular}{|c|c|c|c|c|c|c|}
\hline \multirow[t]{2}{*}{ Characteristics } & \multicolumn{2}{|l|}{ IQ } & \multicolumn{2}{|l|}{ Stress resilience } & \multicolumn{2}{|l|}{ Physical fitness } \\
\hline & Moderate (4-6) & Low $(1-3)$ & Moderate (4-6) & Low $(1-3)$ & Moderate (5-7) & Low (0-4) \\
\hline No parental cancer & Ref & Ref & Ref & Ref & Ref & Ref \\
\hline One parental cancer & $1.00(0.96-1.04)$ & $1.02(0.97-1.08)$ & $0.99(0.95-1.03)$ & $1.09(1.03-1.15)$ & $1.10(1.05-1.16)$ & $1.12(1.05-1.19)$ \\
\hline Two parental cancers & $0.93(0.68-1.27)$ & $0.93(0.6 \mathrm{I}-\mathrm{I} .43)$ & $0.86(0.60-1.21)$ & $1.24(0.83-1.85)$ & $1.14(0.75-1.72)$ & $1.42(0.86-2.33)$ \\
\hline
\end{tabular}

Note: All models adjusted for birth year, conscription year, gestational age and birth weight of the man, paternal educational level, socioeconomic status and age at the man's birth, and maternal educational level, socioeconomic status, and age at the man's birth.

\section{References}

1. Carlstedt B. Cognitive Abilities - Aspects of Structure, Process and Measurement. Göteborg: Acta Universitatis Gothoburgensis; 2000.

2. Carlstedt B. Mönstring och uttagning till plikttjänst och dess relation till provresultat och psykologbedömningar: en jämförelse mellan svenskar och invandrare. [Testing and enrollment to compulsory service in relation to psychological assessments: a comparison between Swedes and immigrants]. Karlstad: Klara AB Tryckeri i Karlstad; 2002. Swedish.
3. Talbäck M, Stenbeck M, Rosén M. Up-to-date long-term survival of cancer patients: an evaluation of period analysis on Swedish Cancer Registry data. Eur J Cancer. 2004;40(9):1361-1372.

4. The National Board of Health and Welfare, The Swedish Cancer Society. Cancer i siffror 2009 (Cancer in numbers 2009). Stockholm: The National Board of Health and Welfare; 2009.
Clinical Epidemiology

\section{Publish your work in this journal}

Clinical Epidemiology is an international, peer-reviewed, open access, online journal focusing on disease and drug epidemiology, identification of risk factors and screening procedures to develop optimal preventative initiatives and programs. Specific topics include: diagnosis, prognosis, treatment, screening, prevention, risk factor modification,

Submit your manuscript here: https://www.dovepress.com/clinical-epidemiology-journal

\section{Dovepress}

systematic reviews, risk and safety of medical interventions, epidemiology and biostatistical methods, and evaluation of guidelines, translational medicine, health policies and economic evaluations. The manuscript management system is completely online and includes a very quick and fair peer-review system, which is all easy to use. 